\title{
Helping Women Cope with Life Behind Bars
}

\author{
Khamsiah Ismail, Ph.D \\ Assistant Professor \\ Correspondence author: +6019-2696456, ikhamsiah@iium.edu.my \\ Nor Faridah Abd. Manaf, Ph.D \\ Professor, \\ faridah.manaf@gmail.com \\ Farizah Jaafar, Ph.D \\ Assistant Professor \\ fishafar@hotmail.com \\ Che Noraini Hashim, Ph.D \\ Associate Professor \\ cnoraini@iium.edu.my
}

\begin{abstract}
Implementation of group therapy in Malaysian prison through Cognitive Behavioural Therapy (CBT) approach is deemed important to improve the psychological well-being of the inmates. Numerous studies had been conducted but most of them provide statistical data based on cross-sectional studies but findings on effect of psychological treatment is still very scarce. This preliminary study aimed to examine the impacts of group therapy on psychological well-being of women prisoners, particularly in Malaysia. Sixteen women inmates from Women Prison in Selangor, Malaysia were chosen and assigned by the prison authority to receive eight group therapy sessions. The respondents in this study were of different race/ethnic groups, different faiths, socio-economical and criminal backgrounds, aged between 27 to 56 years old. Selfreport measures DASS21 was utilized to examine their psychological well-being before and after eight sessions of group therapy in a duration of four months. This study employed a pre- and post-test design study without a control group. Statistical analyses used were descriptive statistics and paired-samples t-test. The results of this study revealed that there were significant differences in psychological variables as indicated by significant decrease level of depression and stress. Although not significant, their level of anxiety has also reduced. The findings of this study the self-belief and psychological well-being of the inmates. The findings could be used to add knowledge and to better understand the inmates and the rehabilitation methods that work for them. It also give some insights if group therapy can be considered as one of the programs that can support the rehabilitation process of the inmates
\end{abstract}

Keywords: Prison, women inmates, group therapy, Cognitive-Behavioural Therapy, intervention, treatment, psychological well-being, depression, anxiety, stress.

\section{Introduction}

Life of marginalized people such as prison can challenge anyone. Being in custody with rigid structure can be an extremely harsh reality for someone who had never been to prison before. When prisoners were asked about what 
is it like to serve a sentence in prison? These were some of their responses (as cited in Quora, 2013): "The toughest part about serving a prison sentence is not being able to tell your loved ones when you would see them at home (Schuhmacher, 2013)"; "Prison is a lonely place. I wake up every day knowing that there is no person there for me to lean on, no one to share my secrets with, no one I can completely trust" (Winfrey, 2014); "Serving a life sentence for some could create mental compensatory mechanisms which serve to soften the impact of the possibility you may never go home" (Griffin, 2013). Other inmate was quoted as saying that "I was scared every day of my life in there" (Brooks n.d. in Stein, 2007).

So, how can an inmate cope or even experience happiness and with the monotonous daily routine, lack of privacy and loss of freedom? While some inmates need help coping with the length of their incarceration, dealing with being separated from loved ones and friends or accepting that the prison is going to be their home for a period of time or forever. Others need to be taught how to live and survive in the prison environment (Crawford, 2003).

Group psychotherapy has always been suggested as part or prison inmates' rehabilitation. An abundant of studies had been carried out to examine the benefits of art therapy and cognitive behaviour therapy with prison inmates in many countries (Kendall, 1993; Gussak, 2004; 2007; 2009, Clark, 2010; Kobayashi, Matsumoto, Imamura, Wada, Ozaki, Takeuchi, Hasegawa, Imamura, Tania \& Adachi, 2011; Akpama, 2013). Meta-analytical studies (Khodayarifard \& ShokoohiYekta, 2010) have revealed that cognitive-behavioural intervention methods have good impact on inmates. These studies demonstrated that there were apparent improvement in mood, behaviour, and problem-solving, an increase in independence, a decrease in depressive symptoms, and also appropriate identity within the group dynamic (Gussak, 2004; 2007; 2009 in Ismail, Abd. Manaf \& Jaafar, 2016).

"Cognitive behavioural therapy (CBT) builds a set of skills that enables an individual to be aware of thoughts and emotions; identify how situations, thoughts, and behaviours influence emotions; and improve feelings by changing dysfunctional thoughts and behaviours" (Cully \& Teten, 2008, p.6). In other words, CBT works by changing people's attitudes and their behaviour by focusing on the thoughts, images, beliefs and attitudes (cognitive processes) and how this relates to the way they behave, as a way of dealing with emotional problems. The therapies also facilitated disclosures of previously suppressed feelings, increased self-insight, and improved ability to deal with the stressful prison environment, and also helps to treat inmates who suffer from anxiety and depression (Johnson, 2008).

Stress, anxiety and depression are two common issues in prison population and these psychological states are often associated with imprisonment experiences among inmates, especially female inmates (Ahmad \& Mazlan, 2014). In support, prison researchers (e.g. Castellano \& Soderstrom, 1997; Unver, Yuce, Bayram \& Bilgel, 2013) noted that prisoners were found to be depressive, anxious, and stressed. In Malaysia, a descriptive analysis by Ahmad and Mazlan (2014) demonstrates that as compared to their male counterpart, the female inmates had higher inclination to struggle from stress and depression. Empirical evidence (Wooldredge, 1999 in Picken, 2012) has also shown that inmates who participate in prison-sanctioned activities experience less depression, anxiety and stress than those who do not participate in such activities.

Particular characteristics in the prison environment might have lessen their coping mechanisms but experience in some psychological-related intervention could probably minimise some of the adverse psychological effects. Training in these areas will support inmates to think positively and improve positive changes in them and most likely heighten their coping mechanisms. This study was meant to shed light on the efficacy of psychological intervention using cognitive-behavioural therapy approach on women prison inmates in improving their mental well-being as indicated by reduction of depression, anxiety and stress levels that could eventually enhance their coping skills. The term inmates and prisoners are used interchangeably to refer to the imprisoned people.

\section{Method}

Prisoners are regarded as a vulnerable population for research study purposes (Bulman, Garcia \& Hernon, 2012) and hence, access is limited. As it did not meet the four requirements of true experiments which are manipulation, control, random assign and random selection, the research design of this study could not be treated as a true experimental study. To fit the condition, the present study (Ismail, Abdul Manaf, Hashim \& Jaafar), followed a pretest-post-test quasi experimental design involving a control group quasi-experimental as 
the design may or may not include control groups (Stone, 2010). Also known as one group study design, data was collected from study participants' before the intervention (pre-), and the same instruments were again used to collect data after the intervention (post-). Inferences on the effect of the intervention were made by observing the statistical difference in the pre-test and post-test results. This approach enables the researchers to determine if the participants experience outcomes of psychological well-being as a result of this program.

\subsection{Sample}

Restrictions with data collection and recruitment of participants in correctional settings - a prison in this study was out of the researchers' control. In the present study, such condition has limited the researchers to collect a larger target sample size to increase the reliability, validity and causality of the intervention. Selection of participants was made via purposivesampling method by the women prison authority based on three main criteria outlined by the researchers which were: (i) Malaysian; (ii) able to read and write either in Malay or English language; and (iii) still serving their term in prison until the intervention ended (approximately in a period of four months).

The respondents in this study were of different race/ethnic groups, faiths, socio-economical and criminal backgrounds, respectively, aged between 35 to 56 years old. Thirty-seven inmates attended the initial or forming stage but some did not stay until the termination stage of the eight sessions for several reported reasons, among which were release from prison, transfer to other prison, and involved in other activities organized by the prison authority.

\subsection{Data collection}

Self-report measures utilized to obtain the psychological well-being data from the participants were the Malay DASS 21 version (Ramli, Salmiah \& Nurul Ain, 2009. The scale which comprises of 21 items - seven items for each respective subscales i.e. depression, anxiety and stress, was reported to have excellent psychometric properties (Ramli, Salmiah \& Nurul Ain, 2009) and have been used in various educational and health service settings in Malaysia. The participants in the group therapy were given tests once before the intervention and once immediately after. The duration between the two data collections was approximately four months (eight sessions). Since only 16 participants stayed until the end of the therapy session, only their data of their pre- and post-intervention was retained and analysed.

\subsection{Intervention Procedures}

Eight 90-minutes sessions of CBT were conducted. The therapy group was trained once in every two weeks. The group members were kept small i.e. between six to seven participants in the earlier sessions, and eventually left with four to five per group upon closure at the end of the therapy sessions. As the fundamental principle of CBT is that thoughts (cognitions) cause peoples' feelings and behaviours, the direction of the therapy conducted for the women prison inmates focus on knowledge/thinking, emotion and behaviour enhancement through discussion, lectures, role playing and assignments. Thus, the activities were designed to undertake several aims as follows:

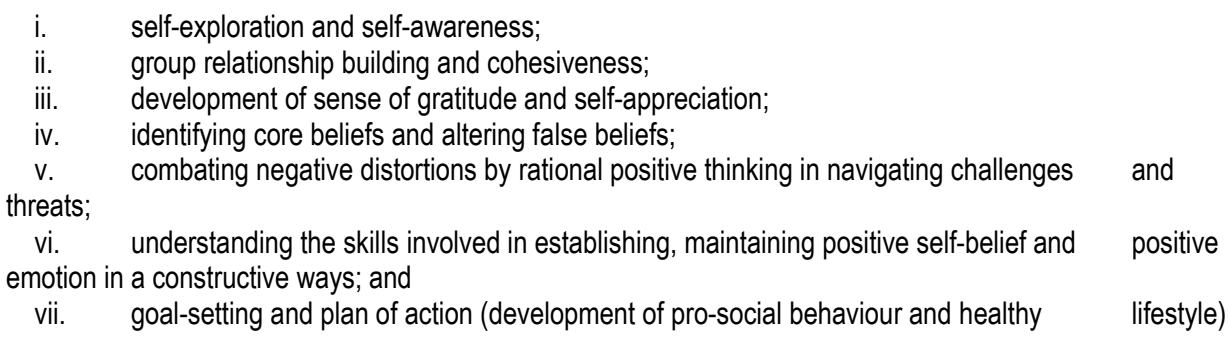

At the end of each session, all groups were gathered for 10 minutes for reflection and reviewing the different cognitive and behavioural skills they have learned using Socratic questioning to prompt (Briggs, 2014; Padesky, 1993) responses such 
as "What have you learned as a result of our time together?"; "Is there anything that was particularly meaningful to you about your time in therapy?"

\subsection{Data Analysis}

Paired samples t-tests was specifically chosen to analyse the data as this study typically consist of a sample of one group of participants that has been tested twice (a "repeated measures" t-test). This test is used to determine whether there is a significant difference between the average values of the same measurement made under two different conditions, before and after treatment. Another reason was the scores are for the same people which suggest there is an underlying relationship between the scores. In sum, this statistical analysis was utilized to compare two means that are repeated measures for the same participants - scores might be repeated across different measures or across time.

\subsection{Findings}

All participants $(n=16)$ in this study were females aged between 26 to 57 years old with different religious and various academic background ranging from lower certificate of education to professional diploma and bachelor's degree. Majority of them (56.25\%) were Muslims and the rest were Christian, Hindu and Buddhist. Prior to their imprisonment they were company director, account manager, religious teacher, nurse, clerk, beautician, boutique manager, music instructor and also house makers.

The DASS measure (overall) and its sub-scales - depression, anxiety and stress utilized used in this study reported high reliability indices of between alpha coefficients (a) .809 to .954 .

As demonstrated in Table 1 below, the the results of t-test inferred that the participants in this study experienced a significant improvements in their overall mental well-being after taking part in the group therapy. In details, the post-test results implied that the participants were significantly less depressed and less stressed at the end of the therapy. As for anxiety, although there was no significant difference in the score, the participants reported lower level of anxiety after participating in the eight sessions of therapy when compared to the condition before the therapy four months before.

\section{Table 1}

T-Test Findings of Mean Changes of Participants' Scores on the DASS after Eight Group Therapy Interventions (N $=16)$

\begin{tabular}{|c|c|c|c|}
\hline & Scale \& Subscales & Pre-test & Post-test \\
\hline i. & $\begin{array}{l}\text { Depression, anxiety \& stress } \\
\text { (overall DASS) }\end{array}$ & $(\mathrm{M}=1.04, \mathrm{SD}=.71)$ & $\begin{array}{l}(\mathrm{M}=.55, \mathrm{SD}=.44), \\
\mathrm{p}>.005, \quad \mathrm{~d}=0.83\end{array}$ \\
\hline ii. & Depression & $(\mathrm{M}=1.12, \mathrm{SD}=.82)$ & $\begin{array}{lr}(M=.52, S D=.48), & t(15)= \\
3.90, p \geq .001, & d=0.89\end{array}$ \\
\hline iii. & Anxiety & $(\mathrm{M}=.89, \mathrm{SD}=.67)$ & $\begin{array}{lll}(\mathrm{M}=.53, \mathrm{SD}=.42), & \mathrm{t}(15)=2.97, \\
\mathrm{p} \leq .01, & \mathrm{~d}=0.66 & \end{array}$ \\
\hline iv. & Stress & $(\mathrm{M}=1.10, \mathrm{SD}=.73)$ & $\begin{array}{l}(\mathrm{M}=.61, \mathrm{SD}=.47) \\
\mathrm{p}>.005, \quad \mathrm{~d}=0.80\end{array}$ \\
\hline
\end{tabular}

\subsection{Discussion and Conclusion}

The purpose of the present study was to investigate if group therapy using CBT approach can help women inmates cope with their life behind bars by improving the psychological well-being. The results of this one group (pre- and post) study design revealed improvement in psychological well-being and was effective in lowering the means of DASS i.e. depression, anxiety and stress. The therapy experienced by the women inmates enable them to adjust better psychologically as exhibited by the results of t-test that their depression and stress indicated significant reduction. Although not significant, the 
result also demonstrated a decrease of anxiety after participating in the group therapy. These discoveries were in tandem with earlier studies in other countries (Apkama, 2014; Khodayarifard \& Shokoohi-Yekta, 2010; Cully \& Teten, 2008; Bully, 2008) which suggest that CBT adjusts the individuals' life for healthier psychological and mental well-being.

Participants came from different background, ethnicity, age, educational level and socio-economic status. The similarities were, they were female and they were put into prison because of their criminal behaviours, either deliberately or inadvertently. Nevertheless, the types of crime they have done were different and the jail term imposed on them also varied. Interestingly however, they shared similar goals in life that is to walk out free and get involved in life activities outside the high concrete wall. In discussing the findings of this study, some verbal expressions of the participants are included as the researchers believed that their words were important to support the empirical data.

In the earlier part of the group therapy there was less communication between participants. Clear enough, they did not know why they were chosen; whether the issues that they share would be kept confidential; what would happen after each session and what they could get from their participation. As the researchers interacted freely with the participants throughout the session as a means of creating an enabling environment for the participants, trust gradually developed. Initial stage is somewhat difficult due to the challenges of life experience in prison and probably the caution of showing emotion or appearing weak/vulnerable (Hatcher \& Noakes, 2010) but once group cohesion was established the inmates become much more playful and relaxed. Group feedback was always welcomed and obtained. "We are counting the days for the next session and looking forward to do the activities and assignments in the therapy," conveyed the participants.

In one of the sessions which was aimed to help the participants contest negative distortions by rising rational positive thinking, they talked about anxiety that they have. For instance, Participant A expressed that she was very apprehensive when she arrived in the prison compound to serve her sentence and did not know much on what to expect. In support, other participants revealed that they were very nervous and anxious but after sometimes when they started to follow the rehabilitation program they overcame their anxiety and began to accept the fact that nothing much that they can do to change the decision. But Participant A said that when she heard talks that she might be released on parole in a near future she shared, "I am getting more anxious now. I wait for the day to come - everyday... when I met a fellow prisoner or bumped into prison officers who knew me...they always ask why I am still here as they thought that I was already released. My disappointment also become stronger....but I must stay strong for my children and grandchildren who are waiting for me to come back home. But I don't know when the day will finally arrive." This condition is in fact in agreement with DeRosia (1998, p. 36) who acknowledges Wheeler's (1961) conception about the typical "U-shaped curve", that is inmates experience stress upon initial entry into prison, resume more usual functioning as they adjust and become acclimated to the situation and environment, an again experience anxiety problems when nearing release.

Findings of this study demonstrate that cognitive behavioural therapies were effective in reducing clients' mental health problems. Through replacing the unfavourable patterns with adaptive cognitive and behavioural ones, these interventions enable the individual to make use of a richer behavioural range in dealing with their issues and to plan their actions (Khodayarifard \& Shokoohi-Yekta, 2010).

Participant $B$ on the other hand hoped to be granted parole. At the end of this session she conveyed that she would work hard to maintain good behaviour, obeyed prison rules and follow all instructions given by the prison authority as violation of any of those rules could reduce the chance of parole. "I have to be apprehensive about being on parole because that is what will keep me functional," she said. Taking a broad view the ability of practising and utilizing it in various situations helps reduce tension and impulsiveness throughout life (Khodayarifard \& Shokoohi-Yekta, 2010). The outcome of the therapy received by the inmates involved in this study support appropriate decision-making, which eventually lead to evasion of criminal behaviour.

Participant $\mathrm{C}$ who was serving a long sentence shared about her misery and her plan when walked out of the prison: "I felt miserable when I first come here...even now I still feel it. After serving my sentence for two years here, I still miss my family... so much. Even though I look forward to my family visit, I feel more stressful when they left. I'm not able to touch them and hug my son. When I'm released from this prison I want to be a better person. I'll do cosmetic surgery on my face, get dental treatment and colour my hair. I want to have good meals with my family and take care of my boy who was two years old when I left him to serve the prison sentence. We'll go for holiday. I want to be a better wife to my husband who visits me every week with my children." Her expression was in agreement with findings of earlier research works (Castellano \& Soderstrom, 1997; Unver, Yuce, Bayram \& Bilgel, 2013) that prison inmates experience depression, anxiety, and stress. 
In fact Crites (1976 in Sobel, 2006) has noted that the most difficult and painful aspect of imprisonment for women is separation from their children. In a more extreme situation, some long term inmates cut themselves off from these relationships as a means of avoiding the anxiety and despair that accompany separation (John Howard Society of Alberta, 1999).

Inmates subjected to any form of therapy differ significantly from those who did not pass through any form of therapy in their psychological adjustment (Crocker, 2002; Loucks \& Zamble, 2000; Melgosa, 2008; Akinade, 2012 in Akpama, 2013). However they also voiced out their worries and concerns about their life after release. They get nervous. They were afraid if they would not fit in the outside world and if their family members and friends would accept them like before. Another crucial aspect was if they could get jobs to support themselves and their family and whether they can get employment upon release. These apprehension and anxieties were indeed valid. "Employment is an important component of the re-entry process. Even more than a steady source of income, jobs can provide a sense of structure and responsibility to former prisoners as they struggle to reintegrate after release. Unfortunately, many will face a difficult path toward finding and keeping employment" (Visher, Debus \& Yahner, 2008, p. 6). Nonetheless, interestingly Participant D gave her suggestion to combat this thought, "I think we can use the knowledge and skills that we have acquired in our vocational training here first like sewing, cooking and baking, to start small business. May be we start on-line business."

Religious belief and practice were their root of strength (Mohamad Jodi, Mohamad, Mohd. Radzi, Che' Seman, A. Rahman, Senin, Ramlan \& Johari, 2014). They also have good relationship with the care takers like the prison warders and officers. Some reported that they have some trusted friends that they shared their emotions and feelings with. This is in fact another aspect of development of pro-social behaviour and healthy lifestyle that they were practising as a coping mechanism and that perhaps they need to be aware of.

The results of this study indicates that psychological interventions through CBT group therapy, can help to improve psychological well-being of the women inmates by reducing their depression, stress and anxiety. As noted in previous research works, the fundamental nature of $\mathrm{CBT}$ is to help prisoners to better comprehend their problems and to cultivate new strategies for tackling them. It is consequently suggested that to improve inmates' psychological health, counselling and psychotherapy, individually or in group need to be provided in all prisons throughout this country. Although counselling is a rather new service and not all prison have the opportunity to have trained and experience counsellors or psychology officers (term used in Malaysian prisons), as suggested by Ismail, Abd. Manaf and Jaafar (2016) prison authorities should employ the services of sessional or locum counselling/psychotherapy practitioner or work with local universities to design and conduct programmes to train the new prison staff to value add the rehabilitation process in the prison and ultimately help the inmates eliminate learned thoughts and behaviours that are undesirable.

The interventions designed for this preliminary intervention work with women prison inmate in this study might work better if prison counsellor were involved as they were expected to know the prison systems better. Follow-up on the psychological progress of these inmates need to be done to establish that those affected are fully adjusted and psychological intervention can be specially designed to help them cope in life, inside and outside the prison.

"Prison is a self-contained environment in which everyone's activity is tightly regulated and monitored" (Bulman, Garcia \& Hernon, 2012, p.1). The women inmates have no choice but to participate in the rehabilitation activities designed for them. Undeniably, they gained a lot of knowledge and skills to the inmates especially through suitable vocational trainings for the Group psychotherapy could be bridge the gap of physical and psychological development much needed by them to teach the women prisoners how to live and survive in the prison environment and help them to cope with the length of their incarceration.

\section{References}

Ahmad, A. \& Mazlan, N. H. (2014).Stress and Depression: A Comparison Study between Men and Women Inmates in Peninsular Malaysia. International Journal of Humanities and Social Science 4(2).

Akpama, E.G. (2013). The effect of cognitive and behaviour therapies on prison and post-prisoninmates' psychological adjustment, In AfokangPrison, Cross River State, Nigeria 
IOSR Journal of Research \& Method in Education (IOSR-JRME)e-ISSN: 2320. Retreived January 1, 2015

Briggs, S. (2014). Socratic Questioning: 30 thought-provoking questions to ask your students. November 8th, 2014 No Comments Features. http://www.opencolleges.edu.au/informed/features/socratic-questioning. Retrieved, November 2015.

Bully, E. Q. H. (2008). Beat crime, antisocial behaviour, bullying, abuse and mobbing with emotional intelligence. Retrieved September 9, 2014. (EQ) (online) http://www.bully.com

Bulman, P. Garcia, M. \& Hernon, J. (2012). Challenges of conducting research in prisons in study raises questions about psychological effects of solitary confinement. National Institute of Justice (NIJ) Journal No. 269. http://www.nij.gov/journals/269/pages/research-in-prisons.aspx. Retrieved, December 2015.

Castellano, T. C. \&Soderstrom, I. R. (1997). Self-Esteem, depression, and anxiety evidenced by a prison inmate sample: Interrelationships and consequences for prison progamming'. The Prison Journal 77 (3): 259-280

Clark, P. (2010). Preventing Future Crime with Cognitive Behavioral Therapy. National Institute of Justice Journal (265) pp.22-25.Retrieved December 12, 2014. https://www.ncjrs.gov/pdffiles1/nij/229888.pdf

Crawford, N. (2003). Helping inmates cope with prison life. Monitor Staff, July/August 2003, Vol 34, No. 7. Print version: page 62 http://www.apa.org/monitor/julaug03/helping.aspx. Retrieved, January 2016

Crocker, J. (2002). The cost of seeking self-esteem. Journal of Social Issues (58), 591-615. [10].

Cully, J.A., \& Teten, A.L. (2008). A therapist's guide to brief cognitive behavioral therapy. Department of Veterans Affairs South Central MIRECC, Houston. Department of Veterans Affairs, South Central Mental IIIness Research, Education, and Clinical Center (MIRECC).

DeRosia, V. R. (1998). Living inside prison walls: adjustment behaviour. Westport CT: Praeger

\section{Griffin, E. (2013). What is it like to serve a life sentence in prison? In Quora, hthps//hww.quora.com. Retrieved January 2016}

Gussak, D. (2009). Comparing the effectiveness of art therapy on depression and locus of control of male and female inmates. The Arts in Psychotherapy 36 (2009), 202-207.

Gussak, D. (2007). The effectiveness of art therapy in reducing depression in prison populations. International Journal of Offender Therapy and Comparative Criminology 5(4). 444-460. Retrieved September 9, 2014.

http://arttherapyinprison.com/wp-content/uploads/2010/09/effectiveness_of_at_in_prison-

inter_journal_on_offender_treatment.pdf

Gussak, D. (2004). Art therapy with prison inmates: a pilot study. The Arts in Psychotherapy, 31(4), 245-259

Hatcher, R. M. \& Noakes, S. (2010). Working with sex offenders: The impact on Australian treatment providers.

Psychology, Crime and Law, 16, 145-167.

John Howard Society of Alberta (1999). Effects of long term incarceration. http://www.johnhoward.ab.ca/pub/pdf/C35.pdf. Retrieved November 2015.

Ismail, K. Abd. Manaf, N. F \& Jaafar, F (2016). Does group therapy work on inmates' self-belief and psychological wellbeing? A study at Malaysian women prison in spiritual, religion and coping - studies on psychological well-being from educational perspective. Eds: Abdallah, S. S. \& Abd. Hamid, S. R. Kuala Lumpur: Institut Terjemahan \& Buku Malaysia 
Mohamad Jodi, K. M., Mohamad, A. F., Mohd. Radzi, W., Che' Seman, A., Rahman, N., Senin, Ramlan, S. F., \& Johari, F. (2014). The Effectiveness of Religious Module in Improving Psyco-Spiritual Health for Women Inmates in Prison. Life Science Journal 2014;11(3) http://www.lifesciencesite.com. Retrieved September, 2015

Johnson, L.M. (2008). A place for art in prison: Art as a tool for rehabilitation and management. The Southwest Journal of Criminal Justice, 5(2), 100-120.

Kendall, K. (1993). Program evaluation of therapeutic services at the prison for women. Correctional Service Canada. Retrieved November 12, 2014. http://www.csc-scc.gc.ca/publications/fsw/fsw14/program-eval_fsw14eng.shtml

Khodayarifard, M, Shokoohi-Yekta, M (2010). Effects of individual and group cognitive-behavioral therapy for male prisoners in Iran. International Journal of Offender Therapy and Comparative Criminology Volume 54 Number 5 October 2010 doi: 10.1177/0306624X09344840.

Kobayashi, O., Matsumoto, T., Imamura, F., Wada, K., Ozaki, S., Takeuchi, Y., Hasegawa, M., Imamura, Y., Tania Y., \& Adachi, Y. (2011). Evaluation of the relapse prevention guidance for drug-dependent inmates: the intervention using selfteach workbook and group therapy in a "private finance initiative" Nihon Arukoru Yakubutsu lgakkai Zasshi. 2011 Apr;46(2):279- 296. Retrieved January 27, 2015.http://www.ncbi.nlm.nih.gov/pubmed/2170681596.

Picken, J. (2012). The coping strategies, adjustment and well being of male inmates in the prison environment .Internet Journal of Criminology.Retreived October 8, 2014.

http://www.internetjournalofcriminology.com/picken the coping strategies adjustment and well being of male inmate s_ijc_july_2012.pdf

Ramli, M., Salmiah M.A, NurulAin M. (2010) Validation and psychometric properties of Bahasa Malaysia version of the Depression Anxiety and Stress Scales (DASS) among diabetic patients. Malaysian Journal of Psychiatry 18 (2). 40-45. http://ejournal. psychiatry-malaysia.org/article.php?aid=65

Stone, E. (2010). T-test paired samples. In N. Salkind (Ed.), Encyclopedia of research design. (pp. 1501 - 1566) Thousand Oaks, CA: SAGE Publications, Inc. doi: http://dx.doi.org/10.4135/9781412961288.n477

Unver, Y., Yuce, M., Bayram, N.,\& Bilgel, N. (2013). Prevalence of depression, anxiety, stress, and anger in Turkish prisoners.J J Forensic Sci. 2013 58(5):1210-8. doi: 10.1111/1556-4029.12142.

Visher, C, Debus, S, Yahner, J. (2008). Employment after prison: A longitudinal study of releasees in three states. http://www.urban.org/sites/default/files/alfresco/publication-pdfs/411778. Retrieved November, 2015.

Schuhmacher, C. (2013). What is it like to servea life sentence in prison? In Quora, https//hww.quora.com/Retrieved January 2016

Stein, K. (2014). Inmate stories: Behind bars, women found a different kind of prison at Tutwiler. http://blog.al.com/wire/2014/01/inmate_stories_behind_bars_wom.html. Retrieved January 2016

Winfrey, T, (2014). What is it like to serve a life sentence in prison? In Quora, hthps:/hww.quora.com/Retrieved January 2016 